\title{
Effect of Electron Beam Irradiation on Polymers
}

\author{
Pradeep K. Singh, B. R. Venugopal, D. R. Nandini \\ Analytical Technology, SABIC Research \& Technology Pvt. Ltd., Sarjapura, Bengaluru-562125, India \\ * Corresponding author email: nandini.dr@sabic.com
}

Received: 10 April 2018 / Revised: 25 April 2018 / Accepted: 30 April 2018 / Published: 5 May 2018

\begin{abstract}
ABSTRA C T
Electron energy loss spectroscopy (EELS) in combination with transmission electron microscopy (TEM) is widely used for chemical state analysis of variety of chemical compounds. High beam sensitivity of substances like polymers hinders the possibility of exploring in-depth analysis provided through the high spatially resolved EELS spectroscopy. In this study, the electron beam irradiation damage on polymers were analyzed with varying dose of electron beams. The stability of the polymers under electron beam exposure depends on the chemical structure on the polymers. In this study the polymers with and without phenyl groups namely Polycarbonate, Polyethylene terephthalate, Polystyrene, Styrene Maleic Anhydride and Polymethylmethacrylate are selected for the comparative degradation study. Effect of varying the electron dose on the stability of polymers were monitored by recording the low-loss EELS spectrum in $\pi$ to $\pi^{*}$ transition and $(\pi+\sigma)$ to $(\pi+\sigma)^{*}$ transition region.
\end{abstract}

Keywords: EELS, polymer spectroscopy, electron beam irradiation, polymer microscopy.

\section{Introduction}

Transmission electron microscopy (TEM) plays a crucial role in understanding the structureproperty-performance correlations for polymers. The chemical state of different elements in a polymeric system can be better understood by combination of electron energy loss spectroscopy (EELS) and TEM, a hyphenated technique to provide the chemical state information at subnanometer resolution [1,2]. It is well known that dispersion and distribution of polymer domains in a blend greatly affects the bulk properties $[3,4]$ and hence it is important to understand the interaction between dispersed phases with the surrounding matrix. Several techniques such as FTIR, NMR, UV-Vis provides insights about chemical interaction between different components in polymeric blend system at the bulk level. TEM/EELS placed in a unique position to study interaction at molecular level with sub-nanometer resolution, which are very useful in understanding the polymeric blends.

One of the common issues associated with electron microscopy for soft materials analysis, is the structural and chemical changes of the polymers during high energy electron beam exposure; known as radiation damage [5]. In general, there are two types of electron-specimen interactions that contribute to damage: (1) elastic scattering of incident electrons by atomic nuclei, and (2) inelastic scattering of incident electrons by atomic electrons. The energy transferred onto the specimen by high energy electrons dissipates as heat and in some cases may lead to appreciable temperature rise, resulting in mechanical instability of the specimen [5]. Another consequence of inelastic scattering is the chemical change in the specimen due to the fact that most polymers are electrically insulators and there is no ready source of free electrons to saturate the radiation-induced free radical. However, soft materials such as polymers having high concentrations of aromatic moieties are more radiation resistant than fully saturated polymers because of the delocalization associated with highly conjugated bonds that provide a source of electron charge and the means to distribute the adsorbed energy over a larger volume of material [5]. 
The chemical changes on the specimen due to radiation damage during TEM observation can be monitored spectroscopically using EELS, which can be attached to TEM. Several studies have been reported on interface studies by TEMEELS, however majority of the reports are on the study of inorganic materials due to their stability under electron microscope [6,7].

The degradation of polycarbonate is widely studied by researchers in the past. Ramani et al [8] proposed the chain-scission as the dominant mechanism of degradation of PC after UV irradiation. Jang et al [9] have also proposed the chain-scission as main cause of degradation during thermal exposure of PC. The activation energy for chain-scission was studied by Abbas et al [10] for thermal degradation of PC. The high energy electron beam induced degradation were studied by Hareesh et al [11] where $8 \mathrm{MeV}$ electron beam was exposed to the PC. The degradation was proposed to be breaking in the chain of the PC. The free radicalization upon electron beam irradiation on PC is proposed by Jaleh et al [12] which causes the degradation by crosslinking of PC.

PET is one of the most widely used polymer for commodity. Several reports are available for the mechanism involved in the degradation of PET. Zhu et al [13] have studied the PET degradation upon irradiation with high energy heavy ions. They reported the destruction of semi-crystalline behavior of PET by ion irradiation. Vasijvea et al [14] have exposed high energy electron beam to PET surface in order to promote the surface functionality such as melting heat, viscosity and surface tension. They also observed the change in wetting selectivity by irradiation with high energy electron beam. The thermal stability of PET was studied by Jabarin et al [15] in different environmental condition. They observed that the air exposure during heating degrades the PET polymer more as compared with $\mathrm{N}_{2}$ atmosphere. They also observed that the temperature higher than $300^{\circ} \mathrm{C}$ degrades PET significantly. Dzieciol et al [16] have also studied the degradation of PET under $\mathrm{N}_{2}$ atmosphere and observed that the weight loss increased significantly with temperature higher than $300^{\circ} \mathrm{C}$. Burrilo et al [17] has reported the chain scission as main degradation mechanism for PET while exposing with high energy electron beam. They also have proposed the radiolysis, cross linking and oxidative degradation for PET after exposed with high energy electron beam.

Varlot el al [18] reported that poly (ethylene terephthalate) (PET) was stable at around $10^{3}$ $\mathrm{Cm}^{-2}$ electron dose for small probe size in EELS analysis. They have also analyzed polystyrene (PS) with varying electron doses and observed that PS was stable up to $10^{4} \mathrm{Cm}^{-2}$ electron dose, however as the dose increases the polymer starts to degrade [19]. In another report, Hitchcock et al [20] utilized low energy electrons for EELS analysis of multifunctional organic molecules and used extended Hűckel molecular orbital calculations for estimation of $\mathrm{C} 1 \mathrm{~s}$ and $\mathrm{O} 1 \mathrm{~s}$ core excitation spectra of PET. Another beam sensitive polymer, poly(methylmetacrylate) (PMMA) has been studied by EELS to evaluate the possibility of chemical transformation during electron irradiation and it was stable till a critical dose of about $10^{2} \mathrm{Cm}^{-2}$ at $77 \mathrm{~K}$ [21].

Thermal degradation of PMMA was studied by Barlow et al [22] where the pyrolysis method was used in the temperature range of $340^{\circ} \mathrm{C}$ to $460^{\circ} \mathrm{C}$. The degradation mechanism was explained on the basis of chain scission of PMMA polymer. The chain scission mechanism by electron beam irradiation is reported by Ismayil et al [23] where amorphization also increased after irradiation with electron beam on PMMA polymer. Moore et al [24] studied the chemical change in PMMA by irradiating deep UV, electron, X-ray and proton beam. They observed that deep UV was least effective as compared with X-ray, electron and proton beam in chains scission of PMMA after irradiation. Nathawat et al [25] studied the effect of low energy electron beam irradiation on PMMA surface and observed that the chain scission is occurring on the surface of the PMMA film.

Egerton et al [26] reported the delocalized radiation damage in polymers, based on fading of the 7-eV energy-loss peak in TEM-EELS analysis. Their study suggested a significant increase in characteristic dose leading to a radiation damage as the electron beam diameter is reduced from $1 \mu \mathrm{m}$ to below $1 \mathrm{~nm}$. The 
Singh et al., J. Mod. Mater; Vol. 5, Issue 1, pp: 24-33, 2018

electron beam radiation damage of other polymers through TEM-EELS technique is also reported in literature [25, 27, 28].

The kinetic mechanism of polystyrene thermal degradation is being studied by Faravelli et al [29] through kinetic models and predicts the radical formation as the route cause of degradation. A detailed review about the thermal degradation of polystyrene is discussed by Guyot et al [30] which indicates that the radical chain formation in polystyrene during thermal exposure in the range of $280-350^{\circ} \mathrm{C}$. McNeil et al [31] have also studied the thermal degradation of polystyrene and suggested intramolecular movement in the start of the degradation followed by intermolecular movement. These leads to the chain scission in the polymer. Molecular weight dependent degradation of polystyrene was studied by Madaras et al [32] and observed that random chain scission coefficient depends on the Mw of PS. The effect of low energy $(<100 \mathrm{eV})$ electron beam exposure to polystyrene was studied by mass spectrometer and a chemical modification was reported by Massey et al [33] The irradiation with electron beam leads to the radical formation and bond breakage and cleavage of the phenyl group from the chain. Svorcik et al [34] have irradiated the polystyrene surface with high energy electron beam and observed scission of aromatic ring followed by cross linking in the polymer.

Though lot of work is reported in literature on the degradation study of different polymers, most of these studies are limited to one or two polymers at a time. Among these, majority of the studies are concentrated on the thermal degradation mechanisms. Even in cases where TEM-EELS has been used for degradation, the conditions used for the study in deferent reports vary significantly making comparison among the polymers difficult for degradation by electron beam. There is a lack of systematic TEM-EELS study of different polymers under similar conditions for understanding their degradation behavior. In this work, we have examined the effect of electron beam irradiation damage on polymers. A comparative analysis was done on the polymers with phenyl group at different positions in the polymer chain to study degradation behavior. Efforts are also made to correlate the findings with non-aromatic polymer (PMMA).

\section{Materials and Methods}

Five polymers were selected for this study, among which four polymers are aromatic and one is without aromatic components in the polymer chain as listed in table 1.

Table 1: List of polymers used in this study with their average molecular weights.

\begin{tabular}{|c|c|c|}
\hline Name & Chemical structure & $\begin{array}{l}\text { The Average } \\
\text { molecular } \\
\text { weight (Mw) } \\
\text { determined by } \\
\text { the GPC } \\
\text { technique }\end{array}$ \\
\hline $\begin{array}{l}\text { Polycarb } \\
\text { onate } \\
(\mathrm{PC})\end{array}$ & & 42500 \\
\hline $\begin{array}{l}\text { Polyethyl } \\
\text { ene } \\
\text { terephtha } \\
\text { late } \\
\text { (PET) }\end{array}$ & & 59537 \\
\hline $\begin{array}{l}\text { Polystyre } \\
\text { ne (PS) }\end{array}$ & $\sim \mathrm{H}_{2} \mathrm{O}$ & 228519 \\
\hline $\begin{array}{l}\text { Styrene } \\
\text { Maleic } \\
\text { Anhydrid } \\
\text { e (SMA) }\end{array}$ & & 52900 \\
\hline $\begin{array}{l}\text { Polymeth } \\
\text { ylmethac } \\
\text { rylate } \\
\text { (PMMA) }\end{array}$ & & 106250 \\
\hline
\end{tabular}

\subsection{Molecular Weight Determination}

The average molecular weight of the polymers was determined by gel permeation chromatography (GPC). The measurements were carried out in a Agilent chromatograph fitted with two PLgel (5 $\mu \mathrm{m}$ MIXED-D, 300 x $7.5 \mathrm{~mm}$ and Part number PL1110-6504) columns and one guard column. For polycarbonate (PC) and polystyrene (PS) samples, chloroform was used as the mobile phase with $\sim 2 \mathrm{mg} / \mathrm{mL}$ (50 $\mu \mathrm{L}$ injection volume) of sample concentration using UV detector at $254 \mathrm{~nm}$ with flow rate of $1 \mathrm{~mL}$ 
per minute. PS standard was used for calculating the molecular weight distribution. Tetrahydrofuran was used as the mobile phase for poly methyl methacrylate (PMMA) with $\sim 2$ $\mathrm{mg} / \mathrm{mL}(50 \mu \mathrm{L}$ injection volume) of sample concentration using RI detector with flow rate of $1 \mathrm{~mL}$ per minute. PMMA (supplied by Agilent) standard was used for calculating the molecular weight distribution of styrene maleic anhydride (SMA) and polyethylene terephthalate (PET). Chloroform with 5\% hexafluoroisopropanol was used as the mobile phase for styrene maleic anhydride (SMA) and polyethylene terephthalate (PET) with $\sim 2 \mathrm{mg} / \mathrm{mL}$ (50 $\mu \mathrm{L}$ injection volume) of sample concentration using UV detector with flow rate of $1 \mathrm{~mL}$ per minute. The average molecular weight of all the polymers are listed in table 1.

\section{$2.2 \quad$ TEM-EELS Studies}

Thin sections $(\sim 100 \mathrm{~nm})$ of the polymers were prepared by Leica FC7 ultramicrotome at room temperature for TEM study. Tecnai F20 TEM operating at $200 \mathrm{keV}$ equipped with post-column GATAN energy filter camera was used for EELS analysis. Multiple low-loss EELS spectra were recorded sequentially from same sample area with 0.2 seconds time interval to observe the radiation damage with varying exposure time. The exposure time was then converted to electron dose in terms of $\mathrm{C} / \mathrm{m}^{2}$. A $2.5 \mathrm{~mm}$ aperture was used for EELS spectrum with 0.1 $\mathrm{eV} /$ channel dispersion and the energy resolution calculated from full width at half maximum of zero loss peak was $0.8 \mathrm{eV}$. It is assumed that the EELS spectrum follows Gaussian profile. The low loss spectrum in region between 2 to $9 \mathrm{eV}$ has been deconvoluted with Gaussian profile to extract the peak positions for the $\pi$ to $\pi^{*}$ transition. The core loss EELS spectrum has not been discussed in this work as the radiation damage on the polymer happens at much smaller time period (within fraction of seconds), which limits the intensity for recording the core-loss spectrum.

\section{Results and Discussion}

Various aromatic polymers given in table 1 are selected for understanding the stability under electron beam exposure. Polymers such as PC and PET contains the phenyl ring in the backbone of the polymer chain, whereas in PS and SMA, the phenyl ring is attached to the polymers side chain. Further structural differences among these polymers is the phenyl ring in PET, PS and SMA is bonded with only carbon atoms whereas in PC the phenyl ring is associated with both carbon and oxygen atoms. We have also included PMMA in the study, a polymer without phenyl group, to compare the extent of radiation damage on polymers with and without aromatic components. The polymers were exposed to the electron beam under TEM until the degradation reached to its saturation. The critical dose for the polymers given in table 2 were calculated by taking the intensity of $\pi$ to $\pi^{*}$ transition at around $5 \mathrm{eV}$ to decreased to $1 / \mathrm{e}$ of its original value.

\subsection{Polycarbonate}

The low loss EELS spectra of PC recorded at varying electron doses are shown in figure 1.
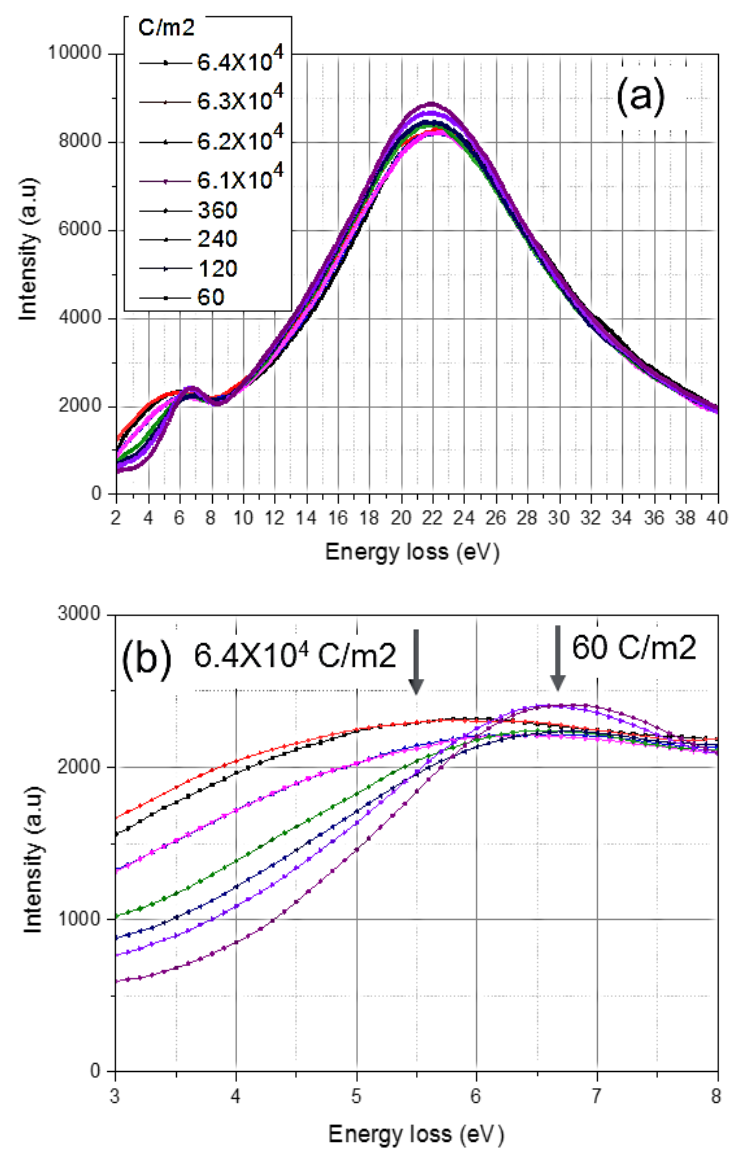

Figure 1: (a) Low loss EELS spectra of PC with varying electron beam exposure time (b) Enlarged area showing the $\pi$ to $\pi^{*}$ transition peaks. 
Singh et al., J. Mod. Mater; Vol. 5, Issue 1, pp: 24-33, 2018

There are two peaks observed in this region, which are common for polymers: peak around 5 $\mathrm{eV}$ from $\pi$ to $\pi^{*}$ transition and peak around 23 $\mathrm{eV}$ from $(\pi+\sigma)$ to $(\pi+\sigma) *$ transition. It has been observed that the peak positions started to shift within fraction of seconds of exposure to the electron beam. The degradation reached to its saturation at dose of $6.4 \mathrm{X} 10^{4} \mathrm{C} / \mathrm{m}^{2}$. The enlarged EELS spectra in $\pi$ to $\pi^{*}$ transition (figure $1 \mathrm{~b}$ ) region shows red shifting of the peaks around 5 $\mathrm{eV}$ during exposure suggesting appearance of additional density of states within $\pi$ to $\pi^{*}$ energy gaps. Furthermore, it is also observed that $(\pi+\sigma)$ to $(\pi+\sigma)^{*}$ transition has been blue shifted as evident from the shift in peak position from 22 $\mathrm{eV}$ to $23 \mathrm{eV}$.

Deconvolution of low loss EELS spectrum from $2.0 \mathrm{eV}$ to $9.0 \mathrm{eV}$ region is further performed to analyze the effect of electron beam irradiation. The enlarged low loss EELS spectrum for PC shown in figure 1 (b) has been deconvoluted by Gaussian profile for freshly exposed region i.e. dose - $60 \mathrm{C} / \mathrm{m}^{2}$ and electron beam damaged region i.e. dose - $6.3 \times 10^{4} \mathrm{C} / \mathrm{m}^{2}$. The deconvolution of freshly exposed area shows two peaks, one at $6.07 \mathrm{eV}$ and other at $7.04 \mathrm{eV}$ from $\pi$ to $\pi^{*}$ transitions as shown in figure 11 . Appearance of two different $\pi$ to $\pi^{*}$ transitions are due to the presence of structural asymmetry as explained by Ritsko et al [35]. The higher intensity peak at $6.07 \mathrm{eV}$ is due to $\pi$ to $\pi^{*}$ transitions from within phenyl ring and the weaker peak at $7.04 \mathrm{eV}$ is due to the different symmetry conditions imposed by alkyl substitution [35]. Similar observations of two different $\pi$ to $\pi^{*}$ transitions due to structural asymmetry are recorded for remaining polymers as well, which are discussed in subsequent sections. The irradiation of electron beam till the dose of $6.3 \times 10^{4} \mathrm{C} / \mathrm{m}^{2}$ shifted the peak towards lower energy loss region, at $3.03 \mathrm{eV}$ and other at $5.12 \mathrm{eV}$.

The deconvoluted spectra indicates that the peak at $7.04 \mathrm{eV}$ in freshly exposed region disappears after electron beam irradiation and a new peak appears at $3.03 \mathrm{eV}$ as shown in figure 11. A slight shift in peak at $6.07 \mathrm{eV}$ towards lower energy is also observed. Electron beam irradiation causes significant modification in the electronic band structure as evident from the FWHM shift for low loss region (figure 11). Apart from the shift in peak position, the FWHM of the peaks also differ significantly. The complete disappearance of peak at $7.04 \mathrm{eV}$ might corresponds to degradation of phenyl group in PC backbone through free radical mechanism as explained by Kosobrodova et al [36] and are shown in figure 2. The formation of the free radicals might have resulted in appearance of new peak at $3.03 \mathrm{eV}$ due to the creation of defect states in the $\pi$ to $\pi^{*}$ transition gap.

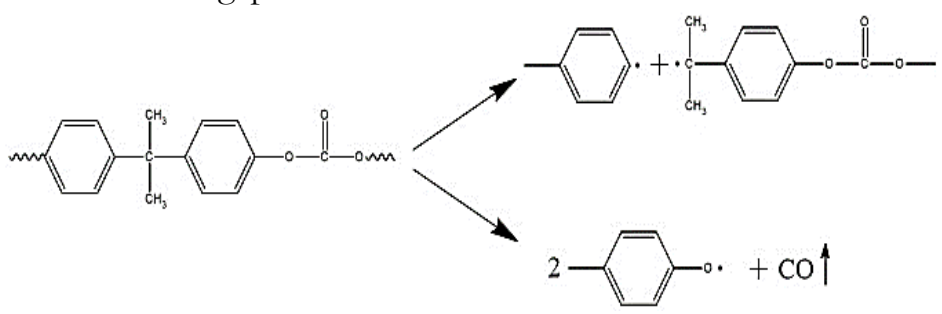

Figure 2: Degradation mechanism of PC on electron beam irradiation.

\subsection{Polyethylene Terephthalate}

We have exposed the high energy electron beam on PET thin film and recorded the low loss EELS spectra with varying electron dose as shown in figure 3 . It can be observed that peaks positions are shifted due to electron beam irradiation as shown in the enlarged spectra in figure 3 (b). The plasmon peak due to $(\pi+\sigma)$ to $(\pi+\sigma)^{*}$ transition has shifted from $22 \mathrm{eV}$ to 23.5 $\mathrm{eV}$ whereas $\pi$ to $\pi^{*}$ transition peak has red shifted from $6.8 \mathrm{eV}$ to $5.8 \mathrm{eV}$. The deconvolution of EELS spectrum from $2.0 \mathrm{eV}$ to $9.0 \mathrm{eV}$ for PET from freshly exposed (at exposure dose - 60 $\mathrm{C} / \mathrm{m}^{2}$ ) and degradation saturated (at exposure dose $-6.9 \times 10^{4} \mathrm{C} / \mathrm{m}^{2}$ ) regions shows small shift in the two $\pi$ to $\pi^{*}$ transition peaks from $5.29 \mathrm{eV}$ to $5.12 \mathrm{eV}$ and $6.73 \mathrm{eV}$ to $6.84 \mathrm{eV}$. This shift indicates that electron beam irradiation does not significantly influence the peak position. Careful examination of the peaks from freshly exposed and degradation saturated regions shows that the peak positions does not alter much but have influence on the FWHM of the peaks as shown in figure 11. These changes in the FWHM might be due to the degradation of the PET through intramolecular dehydrogenation and reorganization of the carbonyl group as suggested by Verlot et al. [28] and shown in figure 4 . 

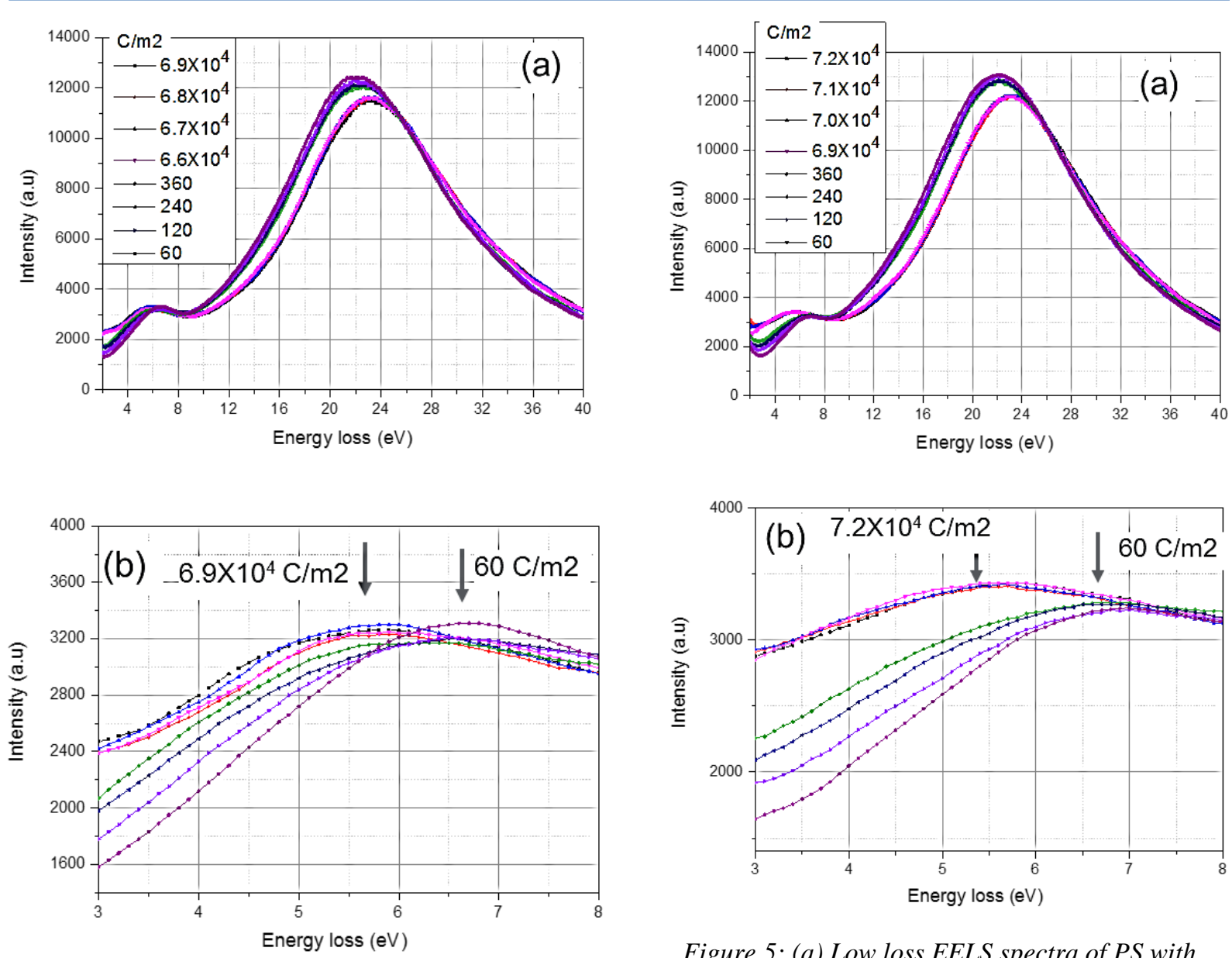

Figure 3: (a) Low loss EELS spectra of PET with varying electron beam exposure time (b) Enlarged area showing the $\pi$ to $\pi^{*}$ transition peaks.

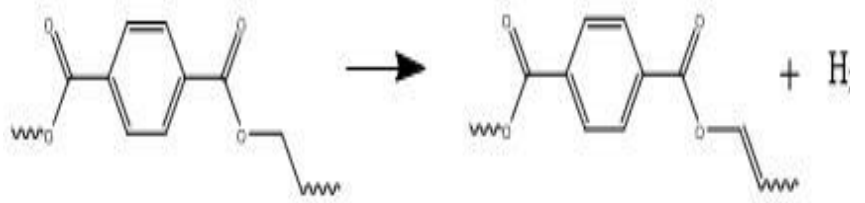

Figure 4: Structural modification of PET on electron beam irradiation.

\subsection{Polystyrene}

Polystyrene polymer has also been investigated for electron beam irradiation sensitivity in this work. The PS has reached saturation of electron beam irradiated degradation with a dose of $7.2 \times 10^{4} \mathrm{C} / \mathrm{m}^{2}$ and the corresponding EELS spectra with $\pi$ to $\pi^{*}$ transition (blue shifted) and $(\pi+\sigma)$ to $(\pi+\sigma)^{*}$ transition (red shifted) are shown in figure 5 .
Figure 5: (a) Low loss EELS spectra of PS with varying electron beam exposure time (b) Enlarged area showing the $\pi$ to $\pi^{*}$ transition peaks.

The low loss EELS spectrum from $2.0 \mathrm{eV}$ to 9.0 $\mathrm{eV}$ is being deconvoluted to quantify the degree of damage due to electron beam irradiation. The FWHM of the deconvoluted spectra with peak position is plotted in figure 11. The deconvolution of freshly exposed area shows two peaks one at $5.62 \mathrm{eV}$ and other at $6.82 \mathrm{eV}$. The electron beam irradiation modified the electronic band structure of PS with new peaks appearing at $4.54 \mathrm{eV}$ and $6.03 \mathrm{eV}$. The Gaussian fitting of the low-loss EELS spectrum indicates that electron beam has significant influence on the electronic band structure of the PS as can be inferred from the deconvoluted spectra in figure 11. Similar to PC, the peak at around $6.82 \mathrm{eV}$ disappears after electron beam damage and a new peak appears at around $4.54 \mathrm{eV}$. As suggested by Varlot et al [19], the observed changes might be due to the formation of chemical bonds with backbone of neighboring polymeric chains (see figure 6). 
Singh et al., J. Mod. Mater.; Vol. 5, Issue 1, pp: 24-33, 2018

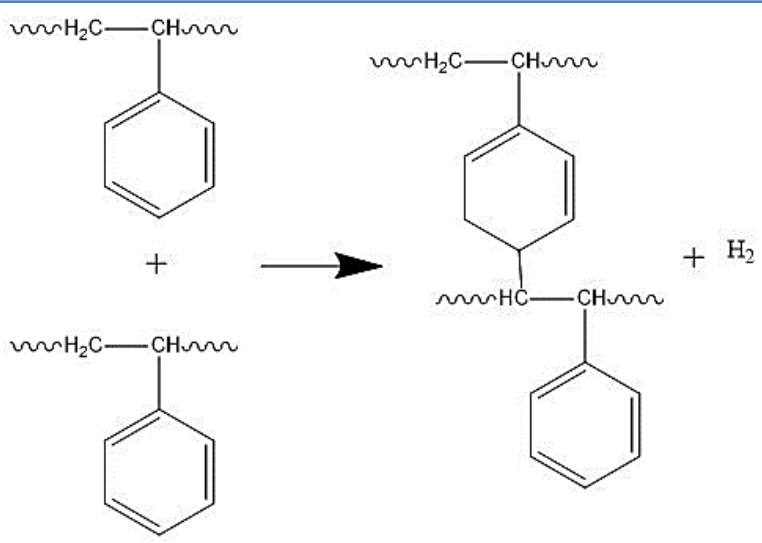

Figure 6: Structural modification of PS on electron beam irradiation.

\subsection{Styrene Maleic Anhydride}

The electron beam irradiation effect on SMA is also studied in this work. The EELS spectra of SMA suggest blue shift in $\pi$ to $\pi^{*}$ transition from $6.9 \mathrm{eV}$ to $5.8 \mathrm{eV}$ and red shift in $(\pi+\sigma)$ to $(\pi+\sigma)^{*}$ transition from $22.5 \mathrm{eV}$ to $23.2 \mathrm{eV}$ as shown in figure 7.
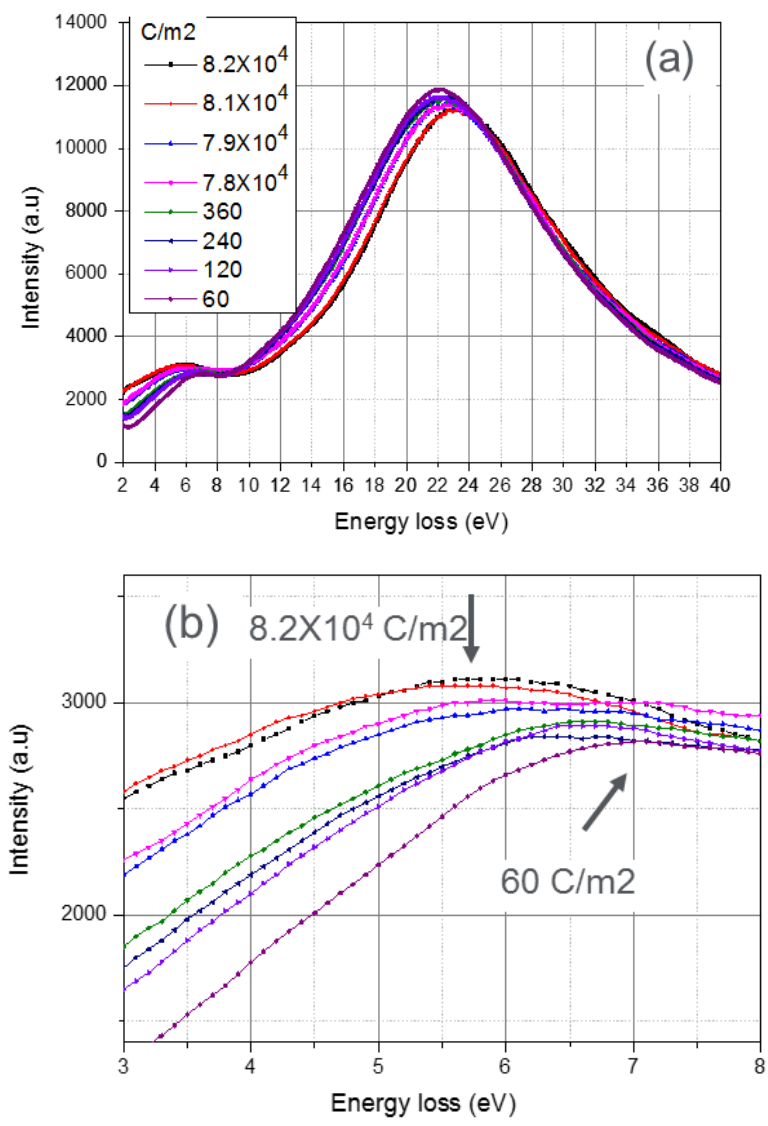

Figure 7: (a) Low loss EELS spectra of SMA with varying electron beam exposure time (b) Enlarged area showing the $\pi$ to $\pi *$ transition peaks.
The deconvoluted $\pi$ to $\pi^{*}$ transition EELS spectrum of SMA from freshly exposed (at dose $-60 \mathrm{C} / \mathrm{m}^{2}$ ) and degradation saturated (at dose $\left.8.2 \times 10^{4} \mathrm{C} / \mathrm{m}^{2}\right)$ regions shows similar trend in the peak as in PET. As observed from the fitting shown in figure 11, the peak position does not change significantly but has influence on FWHM of the peak at around $5.0 \mathrm{eV}$. It appears that meleic anhydride has undergone dehydrogenation process whereas styrene has decomposed through a radical formation during the electron beam irradiation. The mechanism involves in degradation is shown in figure 8 as suggested by Kaczmarek et al. [37].

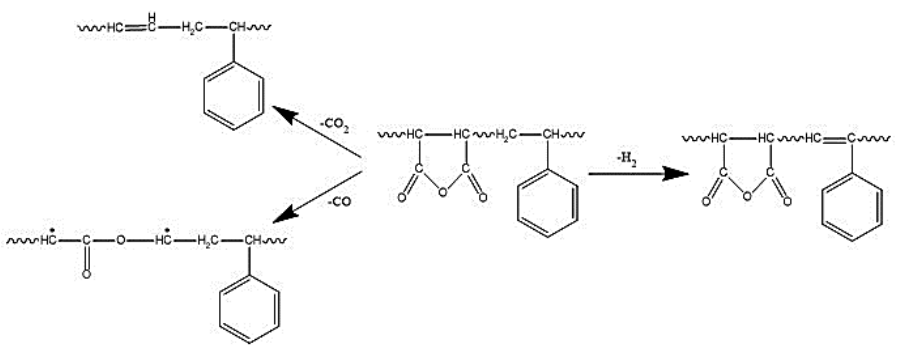

Figure 8: Structural modification of SMA on electron beam irradiation.

\subsection{Polymethylmethacrylate}

We have analyzed the high energy electron beam interaction with PMMA through a series of low loss EELS spectrum and shown in figure 9. In a freshly exposed PMMA sample (dose $\left.-60 \mathrm{C} / \mathrm{m}^{2}\right)$, the $\pi$ to $\pi^{*}$ transition occurs at around $5 \mathrm{eV}$ whereas $(\pi+\sigma)$ to $(\pi+\sigma)^{*}$ transition occurs at around $22 \mathrm{eV}$. Gaussian peak fitting analysis of EELS spectra from $2.0 \mathrm{eV}$ to $9.0 \mathrm{eV}$ region of fresh and degraded PMMA are shown in figure 11. Here too we can observe the presence of two different $\pi$ to $\pi^{*}$ transitions at $5.27 \mathrm{eV}$ and 6.56 $\mathrm{eV}$. However here the peaks are split due to the alkyl substitution in the methymethacrylate back bone [35]. The FWHM of the fitted data plotted against peak position suggest insignificant change in the peak position. The FWHM of peak at around $6.56 \mathrm{eV}$ has increased in degraded samples in comparison to the peak from freshly prepared sample whereas the peak at around 5.27 $\mathrm{eV}$ remains intact. This indicates that the degradation in PMMA causing the additional density of states at around $6.56 \mathrm{eV}$ which might be due to the scissoring of the backbone chain as 
shown in figure 10 [38]. The dehydrogenation process along with decomposition has been taken from the work of Ennis et al [37]. The PMMA having no phenyl ring can be correlated with other polymers used in this study whose phenyl ring is either situated in the chain or side of the chain.
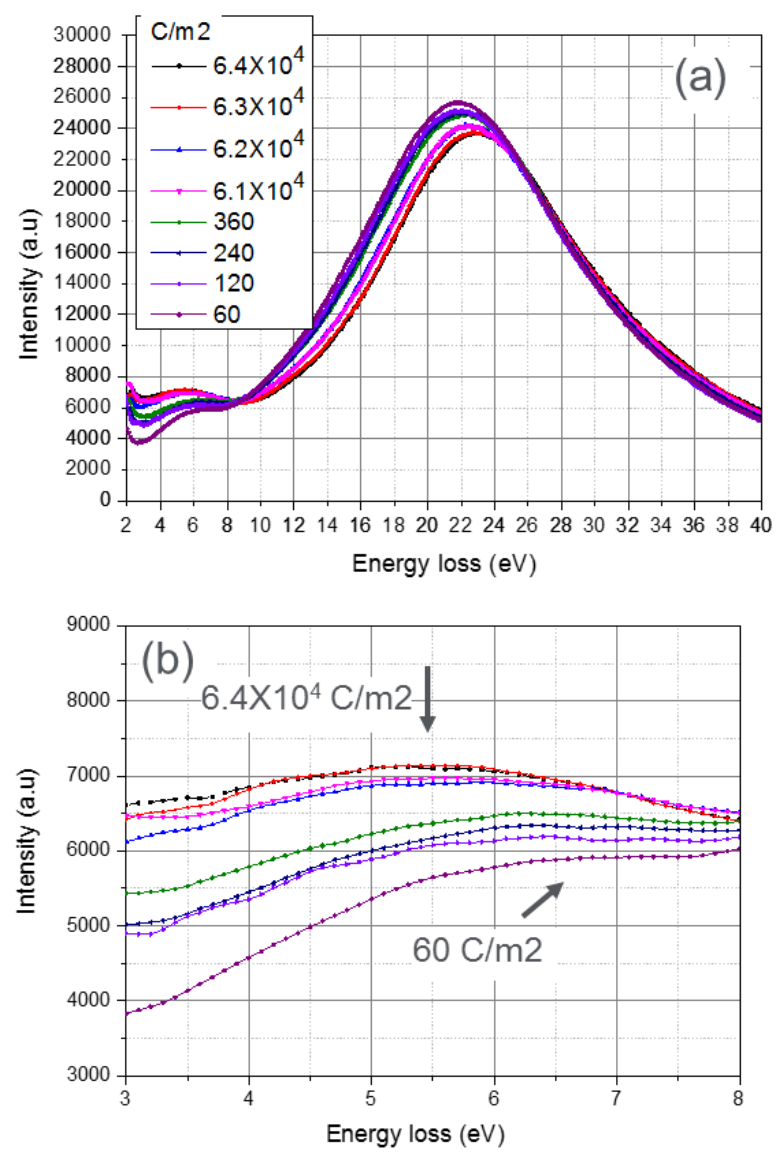

Figure 9: (a) Low loss EELS spectra of PMMA with varying electron beam exposure time (b) Enlarged area showing the $\pi$ to $\pi^{*}$ transition peaks.

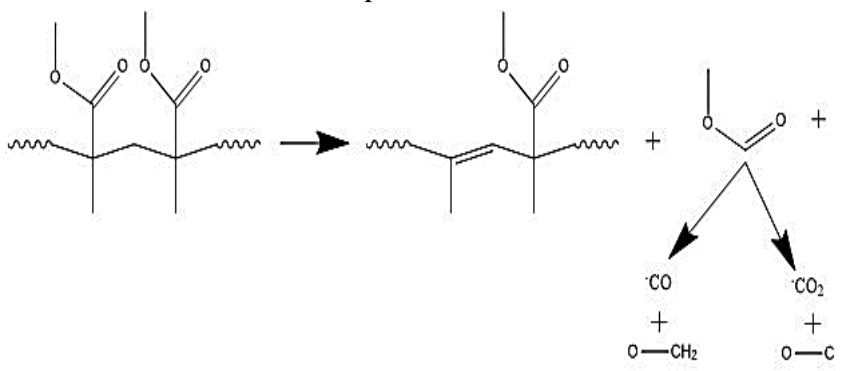

Figure 10: Structural modification of PMMA on electron beam irradiation.

The FWHM from the deconvoluted peak of low loss EELS spectrum from $2.0 \mathrm{eV}$ to $9.0 \mathrm{eV}$ region for all the polymers studied in this work is shown in figure 11. The freshly exposed and electron beam damaged region was used for the deconvolution.
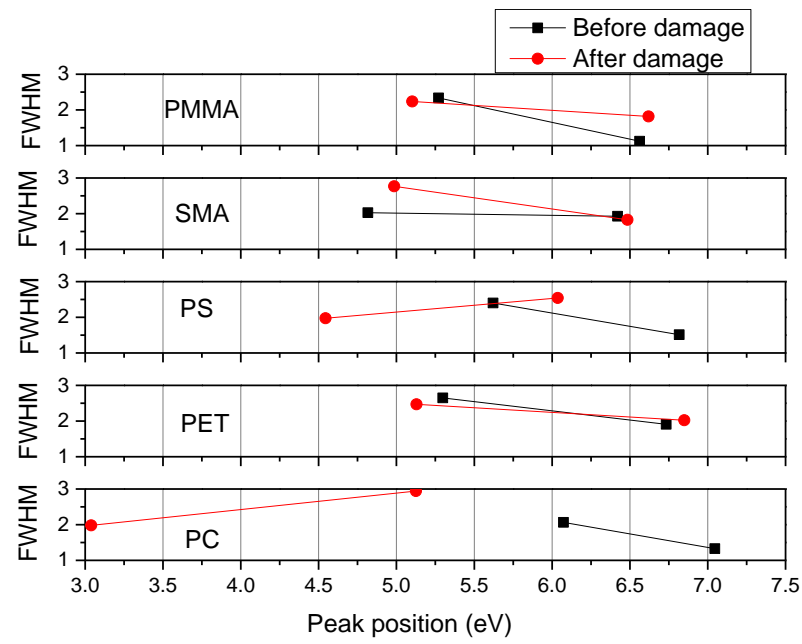

Figure 11: FWHM of the deconvoluted low-loss EELS spectrum from $2.0 \mathrm{eV}$ to $9.0 \mathrm{eV}$ region for all the polymers studied in this work.

We have calculated the critical dose from the fitting of the low-loss EELS spectrum of the polymers given in table 2 . The critical dose is the dose beyond which the intensity of $\pi$ to $\pi^{*}$ transition drops by $1 /$ e of the original value. It is clear from the table that the critical dose is higher for PS and SMA as compared to other polymers. Among the studied polymers, the stability is maximum for SMA and minimum for PC. Both PC and PMMA shows similar critical dose for degradation to be around $10^{2} \mathrm{C} / \mathrm{m}^{2}$ whereas SMA needs maximum dose of around $10^{4} \mathrm{C} / \mathrm{m}^{2}$ for the degradation. The order of stability can be translated as $\mathrm{PC}<\mathrm{PMMA}<\mathrm{PET}<\mathrm{PS}<\mathrm{SMA}$ as deduced from the dose required for degradation.

Table 2: Critical dose of the polymers

\begin{tabular}{|l|l|}
\hline Polymers & Critical dose $\mathbf{( C / \mathbf { m } ^ { 2 } )}$ \\
\hline PC & $10^{2}$ \\
\hline PET & $10^{3}$ \\
\hline PS & $10^{4}$ \\
\hline SMA & $10^{4}$ \\
\hline PMMA & $10^{2}$ \\
\hline
\end{tabular}

In this work, we have examined the impact of electron beam on the structural modifications of the polymers. The specific interest of this study was to utilize the standard TEM/EELS technique for chemical state analysis of various polymers. The study suggests that the 
Singh et al., J. Mod. Mater; Vol. 5, Issue 1, pp: 24-33, 2018

degradation in polymers is unavoidable and the extent of degradation depends on the structure of the polymers.

\section{Conclusion}

All the polymers studied in this work shows degradation after irradiation with high energy electron beam. The irradiation damage has been analyzed by acquiring low loss EELS spectrum of five polymers namely PC, PET, PS, SMA and PMMA. Two regions have been identified to understand the degree of irradiation damage. The $\pi$ to $\pi^{*}$ transition at around $6.0 \mathrm{eV}$ is shifted towards lower energy (red shift) indicating the presence of additional density in the band gap of $\pi$ to $\pi^{*}$ transition after damage. A blue shift has been observed in plasmon peak at around $22 \mathrm{eV}$ for $(\pi+\sigma)$ to $(\pi+\sigma)^{*}$ transition. These shifts can be explained on the basis of modified structure of polymers after being exposed to high energy electron beam. Although all the polymers show similar degradation behavior our study suggests that the degree of damage depends on the structure of the polymers.

\section{How to Cite this Article:}

P. Singh, B. Venugopal, and D. Nandini, "Effect of Electron Beam Irradiation on Polymers", Journal of Modern Materials, vol. 5, no. 1, pp. 24-33, May 2018. doi: $10.21467 / \mathrm{jmm} \cdot 5 \cdot 1 \cdot 24-33$

\section{References}

[1] M. R. Libera, M. M. Disko, (2004), Electron Energy Loss Spectroscopy of Polymers, in Transmission Electron Energy Loss Spectrometry in Materials Science and The EELS Atlas, Second Edition (ed C. C. Ahn), Wiley-VCH Verlag GmbH \& Co. KGaA, Weinheim, FRG.

[2] S. Horiuchi, D. Yin, T. Ougizawa,, Nanoscale analysis of polymer interfaces by energy-filtering transmission electron microscopy, Macromolecular Chemistry and Physics, 2005, 206, 7, 725.

[3] S. Krause , Polymer Chemistry: An Introduction, 3rd Edition (Stevens, Malcolm P.), J. Chem. Educ., 2000, 77, 1,35 .

[4] G. B. Butler Polymers: Structure and bulk properties (Meares, Patrick), J. Chem. Educ., 1966, 43, 7, 396.

[5] M. R. Libera, R. F. Egerton, Advances in the Transmission Electron Microscopy of Polymers, Polymer Reviews, 2010, 50, 3, 321.

[6] R. F. Egerton, Electron Energy-Loss Spectroscopy in the Electron Microscope, Springer US, 2011.

[7] W. M. Stobbs, A. J. Bourdillon, Current applications of electron energy loss spectroscopy, Ultramicroscopy, 1982, 9, 3, 303.
[8] R. Ramani, C. Ranganathaiah, Degradation of acrylonitrile-butadiene-styrene and polycarbonate by UV irradiation, Polymer Degradation and Stability, 2000, 69, 347.

[9] B. N. Jang, C. A. Wilkie, The thermal degradation of bisphenol A polycarbonate in air, Thermochimica Acta, 2005, 426, 73.

[10] K. B. Abbbs, Thermal degradation of bisphenol A polycarbonate, Polymer, 1980, 21, 936.

[11] K. Hareesh, Ganesh Sanjeev, $8 \mathrm{MeV}$ Electron Induced Changes in Structural and Thermal Properties of Lexan Polycarbonate, Materials Sciences and Applications, 2011, 2, 1682.

[12] B. Jaleha, P. Parvin, N. Sheikh, F. Ziaie, M. Haghshenas, L. Bozorg, Evaluation of physico-chemical properties of electron beam-irradiated polycarbonate film, Radiation Physics and Chemistry, 2007, 76, 1715.

[13] Z. Zhu, C. Liu, Y. Sun, J. Liu, Y. Tang, Y. Jin, J. Du, Modification of polyethylene terephthalate under highenergy heavy ion irradiation, Nuclear Instruments and Methods in Physics Research B, 2002, 191, 723.

[14] I.V. Vasiljeva, S.V. Mjakin, A.V. Makarov, A.N. Krasovsky, A.V. Varlamov, Electron beam induced modification of poly(ethylene terephthalate) films, Applied Surface Science, 2006, 252, 8768.

[15] S. A. Jabarin, E. A. Lofgren, Thermal Stability of Polyethylene Terephthalate, Polymer engineering and science, 1984, 24,1056.

[16] M. Dzieciol,, J. Trzeszczynski, Volatile Products of Poly(ethylene terephthalate) Thermal Degradation in Nitrogen Atmosphere, Journal of Applied Polymer Science, 2000, 77, 1894.

[17] G. Burillo, L. Tenorio, E. Bucio, E. Adem, G.P. Lopez, Electron beam irradiation effects on poly(ethylene terephthalate), Radiation Physics and Chemistry, 2007, 76, 1728.

[18] K. Varlot, J. M. Martin, C. Quet, Y. Kihn, Chemical analysis of polymers using transmission electron microscopy/electron energy-loss spectroscopy: The example of poly (ethylene terephthalate), Macromol. Symp. 1997, 119, 317.

[19] K. Varlot, J. M. Martin, C. Quet, Physical and chemical changes in polystyrene during electron irradiation using EELS in the TEM: contribution of the dielectric function, Journal of Microscopy, 1998, 191, 187.

[20] A. P. Hitchcock, S. G. Urquhart, E. G. Rightor, InnerShell Spectroscopy of Benzaldehyde, Terephthalaldehyde, Ethyl Benzoate, Terephthaloyl Chloride, and Phosgene: Models for Core Excitatlon of Poly (ethylene terephthalate), J. Phys. Chem. 1992, 96, 8736.

[21] K. Varlot, J. M. Martin, D. Gonbeau, C. Quet, Chemical bonding analysis of electron-sensitive polymers by EELS, Polymer, 1999, 40, 5691.

[22] A. Barlow, R. S. Lehrle, J. C. Robb, D. Sunderland, Polymethylmethacrylate Degradation Kinetics and Mechanisms in the Temperature Range $340^{\circ}$ to $460^{\circ} \mathrm{C}$, Polymer, 1967, 8, 537.

[23] Ismayil, V. Ravindrachary, R.F. Bhajantri, S.D. Praveena, B. Poojary, D. Dutta, P.K. Pujari, Optical and microstructural studies on electron irradiated PMMA: A positron annihilation study, Polymer Degradation and Stability, 2010, 95, 1083.

[24] J. A. Moore and Jin O. Choi, Degradation of Poly(methyl methacrylate) Deep UV, X-ray, Electron-Beam, and 
Proton-Beam Irradiation, Radiation Effects on Polymers, ACS Symposium Series, 1991, 475, Chapter 11, 156

[25] R. Nathawat, A. Kumar, N.K. Acharya, Y.K. Vijay, XPS and AFM surface study of PMMA irradiated by electron beam, Surface \& Coatings Technology, 2009, 203, 2600.

[26] R. F. Egerton, S. Lazar, M. Libera, Delocalized radiation damage in polymers, Micron, 2012, 43, 2.

[27] K. Varlot, J.M. Martin, C. Quet, EELS analysis of PMMA at high spatial resolution, Micron, 2001, 32, 371.

[28] K. Varlot, J.M. Martin, C. Quet, Y. Kihn, Towards subnanometer scale EELS analysis of polymers in the TEM, Ultramicroscopy, 1997, 68, 123.

[29] T. Faravelli, M. Pinciroli, F. Pisano, G. Bozzano, M. Dente, E. Ranzi, Thermal degradation of polystyrene, Journal of Analytical and Applied Pyrolysis, 2001, 60, 103.

[30] A. Guyot, Recent Developments in the Thermal Degradation of Polystyrenc A Review, Polymer Degradation and Stability, 1986, 15, 219.

[31] I. C. McNeill, M. Zulfiqar, T. Kousar, A Detailed Investigation of the Products of the Thermal Degradation of Polystyrene, Polymer Degradation and Stability, 1990, 28, 131.

[32] G. Madras, G. Y. Chung, J. M. Smith, and B. J. McCoy, Molecular Weight Effect on the Dynamics of Polystyrene Degradation, Ind. Eng. Chem. Res., 1997, 36, 2019.

[33] S. Massey, P. Cloutier, M. Bazin, L. Sanche, D. Roy, Chemical Modification of Polystyrene by Low-Energy $(<100 \mathrm{eV})$ Electron Irradiation Studied by Mass Spectrometry, Journal of Applied Polymer Science, 2008, 108, 3163.

[34] V. Svorcik, V. Rybka, V. Hnatowicz, M. Novotna, M. Vognar, Electron Beam Modification of Polyethylene and Polystyrene, Journal of Applied Polymer Science, 1997, 64, 2529.

[35] J. J. Ritsko, R. W. Bigelow, Core excitons and the dielectric response of polystyrene and poly(2vinylpyridine) from 1 to $400 \mathrm{eV}$, The Journal of Chemical Physics, 1978, 69, 4162.

[36] E. Kosobrodova, A. Kondyurin, W. Chrzanowski, D.G. McCulloch, D.R. McKenzie, M.M.M. Bilek, Optical properties and oxidation of carbonized and cross-linked structures formed in polycarbonate by plasma immersion ion implantation, Nuclear Instruments and Methods in Physics Research B, 2014, 329, 52.

[37] H. Kaczmarek, A. Felczak, A. Szalla, Studies of photochemical transformations in polystyrene and styrene-maleic anhydride copolymer, Polymer Degradation and Stability, 2008, 93, 1259.

[38] C.P. Ennis, R.I. Kaiser, Mechanistical studies on the electron-induced degradation of polymethylmethacrylate and Kapton, Phys. Chem. Chem. Phys., 2010, 12, 14902.
Publish your research article in AIJR journals-

$\checkmark$ Online Submission and Tracking

$\checkmark$ Peer-Reviewed

$\checkmark$ Rapid decision

$\checkmark$ Immediate Publication after acceptance

$\checkmark$ Articles freely available online

$\checkmark$ Retain full copyright of your article.

Submit your article at journals.aijr.in

Publish your books with AIJR publisher-

$\checkmark$ Publish with ISBN and DOI.

$\checkmark$ Publish Thesis/Dissertation as Monograph.

$\checkmark$ Publish Book Monograph.

$\checkmark$ Publish Edited Volume/ Book.

$\checkmark$ Publish Conference Proceedings

$\checkmark \quad$ Retain full copyright of your books.

Submit your manuscript at books.aijr.org 